\title{
Zu den nabatäischen Inschriften von Petra.
}

\author{
Von Enno Littmann.
}

In seinem für die orientalische Altertumskunde außerst wichtigen Buche Neue Petra-Forsclutngen und der heilige Felsen von ferusalem, Leipzig I 912 hat G. DALMAN auf S. 79-107 eine Anzahl von nabatäischen Inschriften behandelt, die er in den Jahren 1904-1910 in der alten Nabatäcrhauptstadt gesammelt hat. Es sind im ganzen 93 Texte, von denen aber nur sehr wenige mehr sind als flüchtig hingekritzelte Graffiti. Diese wenigen sind jedoch zum Teil sehr wichtig.

- M. LIDZBARSKI hat in seiner trefflichen Ephemeris III, S. 276-279 mit gewohnter Sach- und Sprachkenntnis einige Bemerkungen $\mathrm{zu}$ diesen Inschriften veröffentlicht. Miehrere von ihñen treffen mit meinen unabhängig gemachten Notizen zusammen; andere sind mir von grobem Nutzen gewesen.

Trotzdem, wie LIDzBARSKI mit Recht sagt, die Möglichkeit der Nachprüfung beschränkt ist, da DALMAN nur Nachzeichnungen gibt, so glaube ich doch, daß die veröffentlichten Inschriften ein etwas eingehenderes Studium verdienen, als LIDZBARSKI ihnen hat angedeihen lassen. In manchen Punkten, über die LIDZBaRSKI nicht spricht, glaube ich auch noch weiter gekommen $z u$ sein als DALMAN.

Im folgenden stelle ich die Bemerkungen zusammen, die ich mir beim Studium dieser Texte gemacht habe, und gebe zugleich auch Berichtigungen von Versehen und Druckfehlern zu Nutz und Frommen der Benutzer des Buches. 
Ich gebe sic natürlich nach der Reihenfolge der Nummern bei Dalman.

Nr. x. 7u Witr vgl. auch ארות, Nords. Epigr. S. 501, Rec. Arch. Or. II, S. 374; ferner Ovivgos in WadDrNistox $2537 \mathrm{~h}$, şafait. und thamud. ותר in desgl. ותרו in meinen Semitic Inscriptions S. 94. - Das Wort שלם, das in diesen Graffiti so häufig ist, will DALMAAN mit "Heil dem ...." übersetzen im Gegensatze zu NöldEke und EurrNG, die es durch "Grulu wiedergaben. Niemand wird' bestreiten, daß של "Heil " bedeutet, und LIDZBarSKI hat in der Theol. Lit.Ztg. 191 2, Nr. 13, Sp. 386 darauf hingewiesen, welch wichtige religionsgeschichtliche Probleme in diesemWorte enthalten sind. Zugleich ist ja auch der Gruß ein Heilswunsch und hat cine greheimnisvolle Kraft, wie Luk. I0, 4-6 zeigt. "Heil « bedeutet der bekannte englische Gruls hail fellow, well-met, und auch in Deutschen begrüßt man einander mit »Heil!«. Ich glaube aber doch, daß für שלם "Gruß« die bessere Übersetzung ist, da der Schreiber durch dieses Wort den Leser begrüßt.

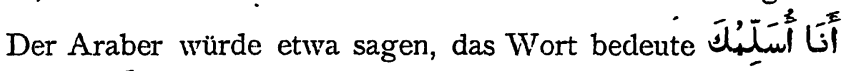
السَّى القارى ألام عليكم In ihm liegt ein das der Schreiber an den Leser richtet, und dieser muß dann natürlich ein 年 Schreiber richten. Wer bei einem Grabe vorbeigeht, sagt

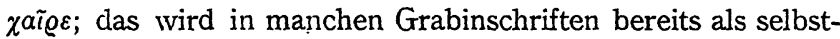
verständlich vorausgesetzt, daher steht in ihnen nur die Ant-

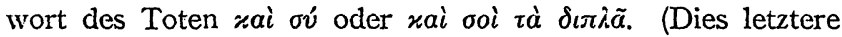
gilt natürlich auch für den, der etwa dem Toten etwas Böses wünschen sollte.) Daß diese Auffassung die richtige ist, wird nicht nur durch die nabatäischen Inschriften selbst bewiesen, wo z. B. wרל קראץ steht, wie DALM. 28, 4, sondern auch durch viele andere Parallelen. Ich verweise nur auf die Formein mit ור in den thamudischen Inschriften und auf das المسلام على مي قرأه in arabischen Inschriften und Graffiti. 
Nr. 2. Am Anfang ist sicher $\mathbb{W}^{\cdots} z \mathrm{zu}$ lesen. $\mathrm{DaB}$ dies das Ende eines Namens ist, hat DALNIAN bereits bemerkt.

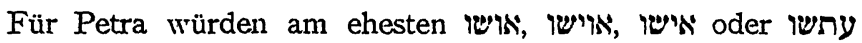
in Frage kommen; andere Möglichkeiten wären אברשו, עבישו, עמות,

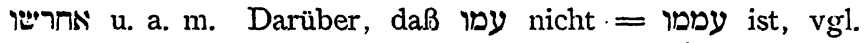
LidzB., a. a. O. S. 276. Der Name "العَ kommt im Tâğ el'Arîs als laqab vor; vgl. Hess, Thamud. Inschr. Nr. 103. Zu עממת vgl. HESS, ibid. Nr. I52.

Nr. 3. Daß עבראיםי = Abd-Isis sei, war mir von vornherein sicher. LIDZBARSKI hat die Frage a. a. O. S. 276 ausführlich erwogen. Er hat ja auch in Petra einc עלימת-אם nachgewiesen und die safaitischen Namen עמדיאם ,ערדיאם scharfsinnig als 'Abd-Is und Taim-Is erkannt. - Die vor dem Namen stehenden Zeichen $|X|$ erkläre. ich unbedenklich als ein wasm, Stammeszeichen. Ich habe, meines Wissens zuerst, darauf hingewiesen, daß diese wustum am Anfange von sinaitischen und thamudischen Inschriften ziemlich häufig sind. Ein ähnlicher Brauch herrscht auch noch heute. So hat z. B. Eutng in Hâjel auf Grabsteinen u. a. folgende

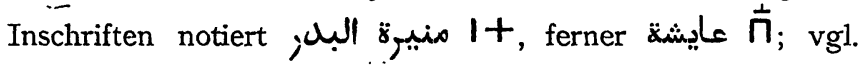
Bd. II seines Tagbuch einer Reise nach Innerarabien (erscheint' demnächst) unter dem 22. November 1883 und dem 16. Januar 1884. Auch ich erinnere mich auf modernen arabischen Grabsteinen dergleichen gesehen zu haben. Bei dem hier in Frage kommenden Zeichen ist das Kreuz $X$ das ursprüngliche wasm, die Striche, die sawāhid, bedeuten, daß neue Familien sich von der alten abgezweigt haben. Sowohl das stehende wie das liegende Kreuz kommt heute noch oft in Stammeszeichen vor. Vgl. zu dem hier Gesagten den Anhang zu meinen Thamud. Inschriften.

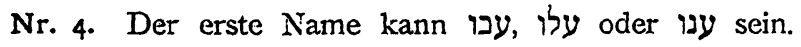
Aber zu y darf nicht $A v \varepsilon o s$ verglichen werden, denn dies

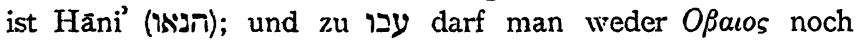
$O \beta \beta \eta$ stellen, denn ersteres ist 'Ubaiy (אביו) und letzteres ist 
I.Iubb (IIT). Am chesten ist, wenn die Kopie richtig ist, an Ableitungen von den arabischen Wurzeln عب oder عie zu denken; von den beiden letzteren sind mir Eigennamen bekannt. - Zu dem Namen manche andere Parallelen. - Das Zeichen vor der Inschrift wird wieder ein wasm sein.

Nr. 5. Ob משלמו als Muslim oder als Musallam zu lcsen ist, ist natürlich aus den nabatäischen Zeichen nicht festzustellen. Aber die Lesung Muslimu (so JAUSSEN) hat ebenso viel Bercchtigung wie Mušallamu (so DALMAN). Ich ziehe Muslim vor, da Mookenos mehrfach in den von mir in der Ḧaurân-Gegend kopierten griechischen Inschriften vorkommt (vgl. Publ. Princet. Exped. to Syria III, Nr. Iı,,

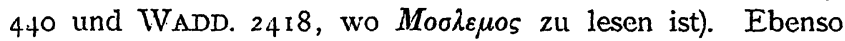
lese ich מחלמו als Mullilim; vgl. Molć,uov in WADD. I969,

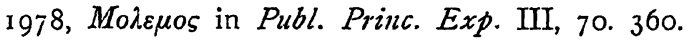

Nr. 6. Die Inschrift scheint schlecht erhalten zu sein. Die Lesung מתורתל stimmt zwar zur Kopie, aber sie ist unverständlich. Ich schlage vor, in der Mitte ein 2 und ein $\aleph z u$ ergänzen, sowie das $\Omega$ in $\Pi z u$ verbessern. Dann

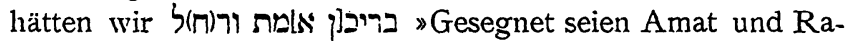

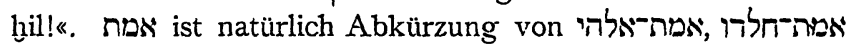
oder-einem ähnlichen Namen. Im Nabatäischen kommt המאל als Frauenname vor, vgl. Nordsemit. Epigr. s. v., im Șafaïtischen als Männername, vgl. Dussaud s. v. Im Arabischen würde 'Abcle als Frauenname entsprechen. Dagegen wäre רח im Nabatäischen neu. Es würde biblischem לח̣? entsprechen. Von derselben Wurzel ist mir im Nabatäischen das Deminutiv רחילית bekannt; vgl. Ephem. II, S. 423 s. v. und Semit. Inscr. S. 92. Es entspricht arabischem Rubailat

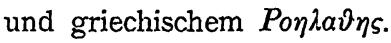

Nr. 7. Der Name Gad kommt wahrscheinlich auch im Șafaïtischen vor. Dort sind a und $y$ einander sehr ähnlich, und in manchen von den vielen ער (vgl. Dussaud s. r.) mag 7 istecken. 
Nr. I4. Statt יפום ist zu lesen; vgl. auch LIDzBARSKI, Ephem. III, S. 277 u. Anm. 4.

Nr. 2r. Es ist schade, daß gerade diese Inschrift in mehreren Punkten zweifelhaft bleiben muß; 'denn, wenn ich recht sehe, enthält sie zwei interessante Götternamen. DALMAN selbst nennt einen Teil seiner Lesung befremdlich. Wenn man jedoch in der 1. Zeile ein $\Omega$ in ein $n$ und in der 2. Zeile ein $\pi$ in ein $\pi$ verbessert, so erhält man folgende Lesung רביר תימו בר (ח)יו קוש ועס(ת) Evistuell kőnte hinter poch ein I stehen. Dann wäre zu übersetzen:

¿Gedacht werde des Taim, Sohnes des Ḧaiy. [ [m Namen des] Qaus und der Astarte Gruß! «

Der Name in ist im Nabatäischen bekannt; vgl. JAUSSEN et SAvigiac, Mission Nr. 45, 51, 52, 64, III, I16. Im Șafaitischen ist $n$ sehr-häufig; vgl. DuSSAUd, s. v.; dazu Acos und Eov WADD. 2160 . Qaus, meist mit $\square$ geschrieben, ist als nabatäischer Göttername ebenfalls bekannt; die Namen Kooa-

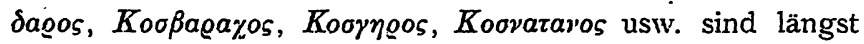
richtig erklärt. Freilich, עסתרת in einem aramäischen Texte bereitet Schwierigkeiten. Nan mülte eben annehmen, daß der Name in Petra direkt aus Kanaan bezogen wäre und $\mathrm{daB}$ man - was übrigens bei fremden Namen auch sonst vorkommt - nach falscher Analogie für das * von עשתרת ein 0 gesetzt hat.

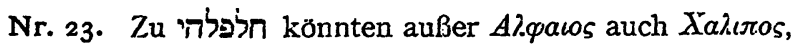

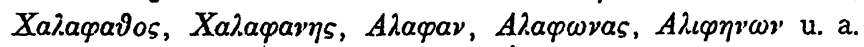
angeführt werden; ferner șafaït. ๆ arab. خَ. Hinsichtlich der Bedeutung wäre auf NÖLDEKE, Beiträge zur semit. Sprachwissenschaft S. 98 ff. zu verweisen.

Nr. 26-27. Nach der Zeichnung wäre jedenfalls der zweite Teil von 26 mit 27 zusammenzunehmen und dann zu lesen:

$$
\text { ורביר אדרם בר ירב }
$$

Aber der zweite Name ist recht unsicher. 
Nr. 30. Ich nehme mit I.IDzbarski an, daß der Name zu lesen ist; vgl. seine Bemerkungen a. a. O. S. 277.

Nr. 3r. Die Inschrift ist zu lesen:

חל חלפו [וזחברתה Halaf und seine Genossin".

An חלרו ist nicht zu denken, da das 7 nie nach links verמלדi Uanden sein kann. Übrigens ist der nabatäische Name sowohl als Masculinum wie als Femininum Hald zu sprechen;

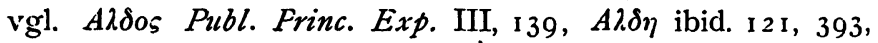

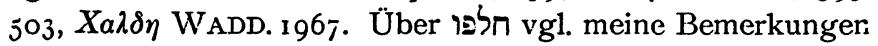
zu Nr. 23.

Nr. 33. Der Name של של ist hier und an allen folgenden Stellen Sullai zu lesen; vgl. LIDZBARSKI, a. a. O. S. 277. Die griechische Form ist nicht nur $\Sigma v \lambda \lambda$.aıs, sondern aueh $\Sigma o$.$\lambda \varepsilon o s ; \mathrm{vgl}$. die von mir veröffentlichte Bilinguis im Florilegium de Vogïé p. 388, sowie Rev. Bibl. XII (1903), S. 428, Nr. 6. Dagegen ist $\Sigma o \lambda \varepsilon o s$ arabisch Șulaih.

Nr. 34. Dalman umschreibt אירען, aber seine Zeichnung hat nur אירן אירן. An und für sich wäre ein Name אירען sehr gut möglich. Aber wenn das $y$ wirklich auf dem Steine fehlt, so kann man auch an אירן denken; vgl. thamudisch אר, Hess, a. a. O. Nr. 89. Prof. NöLdEkE denkt bei אירן auch an أيْل

Nr. 35. Diese außerordentlich wichtige und interessante Inschrift ist von allen Herausgebern bisher mißverstanden. Es ist gut, daß neben der Kopie von JAUSSEN die von DALMAN veröffentlicht ist, und vor allem, daß-DALMAN den Ort der Inschrift genauer beschrieben hat; denn nur dadurch. ist der Anfang und die Erklärung der ersten Worte gesichert. D. sagt nämlich, die Inschrift befinde sich »auf dem Felsboden neben einem kleinen Troge«. Demnach lese ich den Anfang mit Sicherheit רה אוגא. Der Verbindungsstrich zwischen dem $\lambda$ und dem $\boldsymbol{N}$ ist nur zufällig. Dann folgen 7 und ein Verbum. Nach der Kopie JaUSSEN's müßte man נרב lesen; aber dies Verbum ist nọch nicht sicher im Ara- 
mäischen nachgewiesen. Ich habe auch an נרר 》geloben" gedacht, aber der letzte Buchstabe muß nach beiden Kopien ein $ב$ sein. Daher wird LIDzBarSkI's brieflicher Vorschlag, zu lesen, das Richtige treffen. Der Name des Spenders ist תימו; der Name seines Vaters ist שמיתו. Es ist mir unbegreiflich, wie man einen Namen wie שמיתתאלה, der doch sozusagen den Stempel der Unwahrscheinlichkeit auf der Stirn trägt, für möglich gehalten hat. Vielmehr ist das zweite $\Omega$ einfach in 7 und $\zeta$ zu zerlegen; der Kopf des 7 ist zu nahe an das $\rfloor$ gerückt, und man sah $\_$für éinen Buchstaben an. Das' zu Anfang der dritten Zeile ist in beiden Kopien enthalten, also darf man es nicht streichen. Somit ist das Ganze zu lesen:

ד רה אגניא רי קרב תימו brachte Taim,

der Sohn des Šumait, für die Götter

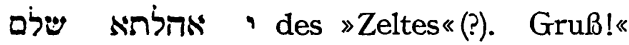

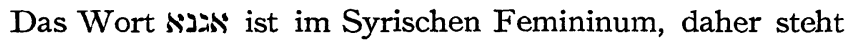
hier auch רה. Es bezeichnet zwar im Syrischen hauptsächlich den "Krug «, wird aber dort auch übertragen gebraucht. Im Hebräischen ist es jedoch ein »Becken, Waschbecken «, und das paßt vorzüglich zu dem von DaLmaN beschriebenen »Trog «. Daß die אגניא hier religiöse Bedeutung hat, geht aus der Inschrift hervor; vgl. dazu die "Spendeschalen " in Dalman, Petra I, S. 81 f. - Die Lesung אהלתא ist nach JAUSSEN's Kopie- sicher. Ich erinnere vorläufig nur an die

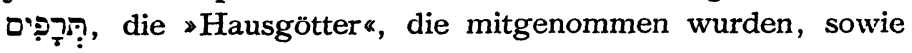
an den religiösen Gebrauch des Wortes aber אהלתה Ortsname. Nach DalmaN's Kopie könnte man auch אלהים אלהא lesen, wie mir Prof. NÖLDEKE mitteilt; aber das ist sachlich unwahrscheinlich. - Hier könnte שלם am Schlusse vielleicht auch den Segenswunsch für den Stifter bezeichnen.

Nr. 36. In dieser unvollständigen Inschrift ist wohl zwischen den beiden letzten Zeichen keine Trennung zu

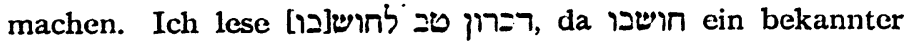


nabatäischer Name ist; vgl. JAUSSEN et SAvigivaC, Mission nah. 1, I (CIS IJ, 199) und 2, 2. Dann ist naturlich auch in JuUssiv's Kopie (CIS 426 E) der Schluf anders \%u lesen, d. h. dic Buchstaben ob sind in i zu verbessern. Das ist bei cliesen Graffiti leicht möglich.

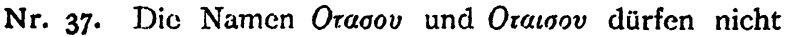
mit $\pi$ und $\vartheta, \vartheta$ und $\tau$ einander fast ausnahmslos. Wo, wie bei Tavtos, Moyıtos u. ä. Ausnahmen zu konstatieren sind, scheinen besondere phonetische Gründc vorzuliegen; denn daneben

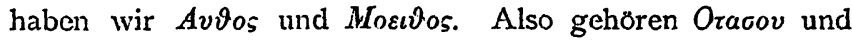

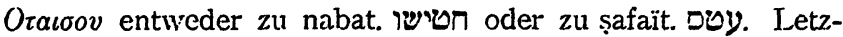
teres ist mir deshalb wahrscheinlicher, weil dem Șafa ein Dur mit $\dot{\boldsymbol{c}}$ entspricht; denn im allgemeinen wird das $\dot{\zeta}$ im Griechischen nur dann nicht ausgedrückt, wenn eine Liquida in der Nähe steht.

Nr. 40. Daß. מענו מעו austanden sein sollte, ist ganz unwahrscheinlich. Eher ist $19 \mathrm{zu}$ lesen und zu dem arabischen Stamm كن zu stellen, von dem mehrere N'amen gebildet sind. Im Safa ist $p$ als Stammes- und Personenname recht häufig. Den las man bisher als Kaun; angesichts dieses בנו und der arabischen Namen bin ich jetzt eher geneigt, ihn Kinn (Kuınn) zu lesen.

Nr. 4r. Der Name sist Amat-Hald zu lesen; vgl. oben $z u$ Nr. 3x. Die Frage, wessen Frau sie war, läßt sich jedenfalls nicht nach Nr. $j_{1}$ beantworten; denn dort steht am Anfang nicht שלם של sondern.

Nr. 42. Die Lesung לבסא ist sehr unsicher. Vielleicht ist das unvollständige Zeichen am Anfang des Wortes zu einem $\aleph z u$ ergänzen. Dann hätte man Nos; mit yל zusammen עלים-אםא על Diener der Isis". Es scheint, daß der fremde Gottesname in verschiedener Weise wiedergegeben wurde.

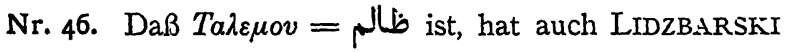


erwähnt. Hätte DALMAN die Stelle WADD. $246_{4}$ nachge-

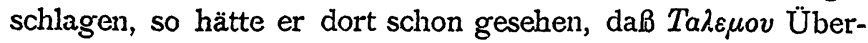
tragung von bلهو ist.

Nr. 49. Ob der neuarabische Name 'Abejsi zu עבישו, gehört, ist doch fraglich. Denn die nabatäischen Namen sind wohl von der Wurzel عبش (mit (m) abzuleiten, wie sich aus der șafaïtischen Form עבשת ergibt; vgl. meine Semit. Inscrs. S. 164. Aber von عبm kommen ja auch Namen vor.

Nr. 5r. Die Inschrift kann nach der Kopie nur שלם

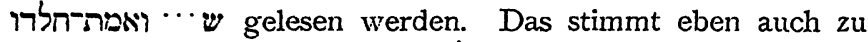
den anderen Inschriften, da של kaum je zwischen zwei Namen steht, sondern entweder vor oder nach den Namen. Nun mag aber immerhin $ש$ zu ergänzt werden, sodaß man aus "שמתזיח" ein Ehepaar machen könnte; aber mit kann auch ein ganz anderer Name beginnen. Vgl. oben zu Nr. 4I.

Nr. 53. Der Name ענמו kann Ġanm, oder Ġānim, oder Ġannām sein, aber nicht Ǵanām. Dementsprechend grie-

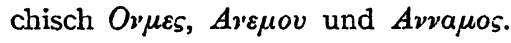

Nr. 55. Ich lese diese Inschrift trotz ihrer schlechten Erhaltung doch ziemlich sicher שלים מליבת בר מיור Zu "Najor" vgl. JaUSSEN et SAvignac, Mission S. 220, Nr. 70.

Nr. 56. Über die partielle Assimilierung des $D$ vor $D$ im Namen קומס vgl. jetzt auch meine Bemerkungen in Deutsche Aksum-Exped. IV, S. 68, Nr. 59.

Nr. 57. Die Inschrift wird zu lesen sein:

"Gedacht werde des Hुalafallāh und seines Genossen in Gutem!

Die Inschrift ist schlecht erhalten, daher kann man ebenso gut ein 1 ergänzen, wie man ein 2 in בטכ ergänzen muß. Der Wechsel von $\Omega$ und $\Pi$ ist uns auch sonst schon begegnet. Nr. 58. Über אצפח vgl. die Bemerkungen LIDZBARSKIs, 1. c. S. $277-278$.

Nr. 59. Am Anfang des Kommentars ist Márab Druck- 
fehler für Ma'rab. Statt ח ist nach der Kopie eher  Aoovpai $\eta$ Publ. Princ. Exp. III, Nr. 422, das ich früher als 'Așūnat crklärtc. Man weiß nicht recht, ob man den Namen cler Wurzel oder der Wurzel خصر zuweisen soll.

Nr. 60. Der Name Frauennamc. Dazu kommt, daß man im nabatäischen Arabisch cher עים erwarten würcle; vgl. unten zu Nr. 67. Natürlich denkt man sofort an den Götternamen eئم vgl. IVELlfiAUSEN, Reste arab. Heidentums ${ }^{2}$ S. 66. Aber Ableitung und Zusammenhang sind unklar.

Nr. 6r. Am Anfang wird $\square$ doch als $ש$ zu lesen sein; auch LIDZBARSKI, 1. c. S. 276 , Anm. 3 bezweifelt das 0 . Man braucht nur anzunehmen, daß die beiden Querstriche cles $*$ versehentlich miteinander verbunden sind, sei es im Original oder in der Kopie, oder daß vielleicht auf dem Steine durch Verwitterung eine Verbindungslinie entstanden sei; dann hat man schon $\square$. Überdies steht in der Kopie ein Fragezeichen über dem $D$.

Nr. 64. Ich glaube in der Tat, daß רחתימו רחימו, nicht $z u$ lesen ist; Wechsel von $\Omega$ und $\pi$.

Nr. 65. Die Zeichen hinter בר sind wohl zu einem Buchstaben $z u$ verbinden. Zunächst denkt man an $\Omega$, also ברת, aber der vorhergehende Name עירו ist ein Masculinum. Daher wird vielleicht ein $\aleph$ zu lesen sein, und man hätte בר אבגלבו אבלבו אommt in CIS II, I82, 184 vor.

Nr. 66. Natürlich ist קיני zu lesen statt Nיp; so auch LIDZBARSKI, 1. c. Auch die Namen קייוז im CIS (vgl. Index) halte ich nicht für richtig. In beiden Fällen lese ich $\Xi$ statt $p$, daher Fâyiz und Fuyaiz (oder Fiyaiz).

Nr. 67. Ich lese שר(ח):אל בר עימו. Der erste Name entspräche dem bekannten سكرר in der Bilinguis von Harrân. Aber die etymologische Erklärung des Namens ist noch nicht

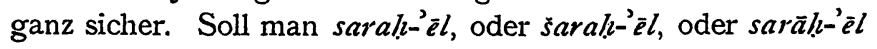
("Gott hat Ruhe gegeben «) oder noch anders lesen? Ein 
kommt im Șafaïtischen vor; vgl. meine Semit. Inscrs. S. I52, Nr. 76. Daß ע zu lesen sei, ist mir ganz sicher; das Zeichen zwischen $y$ und $D$ ist ein deutliches '. Über den Namen vgl. DALMAN's Bemerkungen.

Nr. 68. Der Name שיעהלהי ist sonst doch nicht ganz unbekannt, denn WADD. 2298 hat die entsprechende griechische Form $\Sigma_{j}$ aldas. Hier sei auch gelegentlich des Wortes עי bemerkt, daß Daldian in Petra I, S. 5 I, Z. 6 behauptet, שיעהלקום sei »nach der Inschrift von tell rārie der 'gute und wohlbelohnende Gott, der keinen Wein trinkt" «. Das ist nicht richtig. Diese Charakterisierung des Gottes steht nicht in der nabatäischen Inschrift von il-Gâriye, sondern in der von mir gefundenen palmyrenischen Altarinschrift; vgl. Semit.

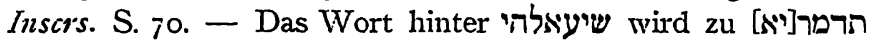
zu ergänzen sein.

Nr. 69. Wenn die Striche in der zweiten Zeile etwas $z u$ bedeuten haben, so wäre [I] ע zu lesen. Der Name ist bekannt.

Nr. 71. Die Inschrift ist sehr merkwürdig. Wenn nicht alles täuscht, so haben wir hier ein Graffito mit ähnlichem Inhalt wie manche șafaitische und thamudische Graffiti, in denen erzählt wird, was dem Schreiber oder dem Urheber der Inschrift begegnet ist. Denn die 2. Zeile hat deutlich die Buchstaben פגע אשר רם (oder am Schlusse etwa רמא, bzw. 127). Und da ist die Übersetzung $\gg$ Es traf einen Löwen Rām« sehr verlockend. Mischung von aramäischen und arabischen Worten ist auch sonst bekannt; zur Not könnte man auch فبع in der arabischen Bedeutung nehmen und dann lesen sein Löwe jagte den Rām in Angst «. Beide Formen, רמו und, sind bekannt. Hier könnte dann auch wieder שלס in der 1. Zeile mehr als ein bloßer Gruß sein, da man Ableitungen der Wurzel wلم sehr häufig bei der Begegnung mit wilden Tieren gebraucht. Aber das Ganze ist $\mathrm{ja}$ leider recht unsicher. $\mathrm{Zu}$ dem Inhalte des Graffito wären dann zu vergleichen die thamudische Inschrift in meincr Zeitschr. f. Assyriologie. XXVWr. 
$\Lambda$ blhandlung über clicse Inschriften, S. 25, wo von einer I.öwenjagd dic Redc ist; fernor Deutsche Aksum-Exped. IV, S. 69, Nr. 03, cin Graffito, in dem jemand sagt, er habe eine Schlange gretötet; und in den von mir kopierten Safâ-Inschriften wird z. B. gesagt בלמה האיר "der Löwe hatte ihn verwundet"; vgl. auch Rec. Arch. Orient. VII, S. 2 I6.

Nr. 73. Auf dic Wichtigkeit dieser Inschrift und auf die Bemerkungen DalmaN's und LIDzBaRski's über den מרזח sei besonders hingewiesen.

Nr. 74. DALAAAN's Lesung ist ganz unsicher, wie auch LIDZBARSKI hervorhebt. Ich glaube, da? hier drei Personen sich verewigt haben. Man braucht übrigens nur ein 7 in Z. 2 einzufügen und dann liest man ganz glatt עברית ויאשית

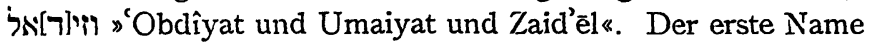
ist neu, aber unwahrscheinlich; er wäre ein doppeltes Hypokoristikon von עבד, mit , und mit ח gebildet. Der Name אמית kommt sonst als Frauenname vor; vgl. Nords. Epigr., s. v. und JAUSSEN et SAVIGNAC, Mission S. 199, Nr. 36 . Aber als Männernamen kennen wir Umaiya aus der arabischen Geschichte. - Zu vis ve die bekannten anderen

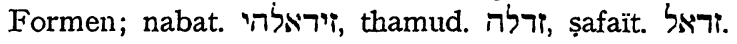

Nr. 75. Statt קינו zu lesen; vgl. oben zu Nr.66.

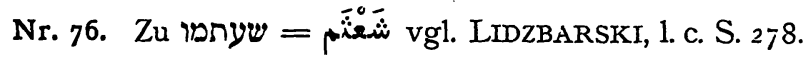

Nr. 80. Die Inschrift ist zu lesen מערו בר אתלמו]. Die

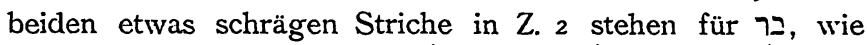

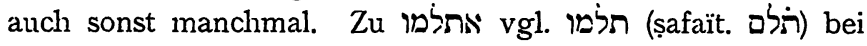
Dalman Nr. 46.

Nr. 82. Statt יבי"ישר lese ich deutlich. Man braucht nur den ersten Buchstaben in der 2. Zeile unten links zu schließen und die Querlinie des vierten Buchstaben gerade $\mathrm{zu}$ ziehen.

Nr. 83. Die Lesung LIDzBaRski's גריגו statt DaLMIAN's יריבו ist jedenfalls viel besser; die Inschrift ist aber recht unsicher. 
Nr. 84. Trotz der schlechten Erhaltung der Inschrift wage ich folgende Lesung:

$$
\begin{aligned}
& \text { רנביר]ין [ש]לי [ר]עוד]ר] } \\
& \text { בני בוזיאה שלם }
\end{aligned}
$$

Der Name בוז ist aus Hegra, aus dem Neuen Testament

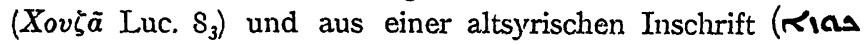
ZA XXVII, S. $3 \delta_{1}$ ) bekannt. Ob er aber wirklich hier gestanden hat, ist mir noch sehr zweifelhaft, während die Lesung der I. Zeile mir ziemlich sicher erscheint.

Nr. 86 u. 88 scheinen in der Tat Zeichen aus einer nichtnabatäischen Schrift zu enthalten. Aber sie sehen eher thamudisch denn șafaïtisch aus. Unter dieser Voraussetzung könnte man in 86, Z. 2 לחרית lesen und in 88, Z. 2 am Ende 7. ח. Letzterer Name ist thamudisch belegt; vgl. J. J. HEss, Entzifferung Nr. 42. Thamudische Inschriften in Petra wären ein Seitenstück zu den șafaitischen in Umm iğg-Ğimâl. Aber die Sache ist doch recht unsicher. Wenn meine Vermutung richtig ist, so wäre Hutaif wohl von der südlichen Nabatäerhauptstadt, Hegra, nach der nördlichen, Petra, gekommen. In beiden Fällen scheint חורו die merkwürdigen Zeichen veranlaßt zu haben. $\mathrm{zu}$ sein.

Nr. 87. Der Name scheint mir-ziemlich deutlich ע]רי[ריטים

Nr. 92. Der fragmentarische Zustand dieser für die Geschichte des nabatäischen Königshauses so außerordentlich wichtigen Inschrift ist besonders $z u$ bedauern. Wie LIDzBARSKI, 1. c., S. 279 sagt, ist eine erfolgreiche Nachprüfung der Lesung nur nach dem Original möglich. $\mathrm{Daß}$ in Z. 6

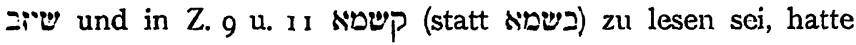
ich unabhängig ron LIDZBARSKI notiert. Ein ähnliches $p$ ist mir auch sonst begegnet; so $2 . \mathrm{B}$. in meinen Nabataean Inscriptions, Leiden 1913, Nr. 32 und 106. Vortrefflich ist die Vermutung IIDzBARSKI's, daß in חבתא (Z.5) der Name des Ortes, Hubța, enthalten sein könne.

Den Namen עבראליאי (bzw. transkribiert DALMAN 
in Nr. 42 'Abululgajā, S. 104, Z. 7 'Abdulgè, S. 104, Z. 12 'Abdelge. Dic gricchische Schreibung Mai) $\gamma \alpha$ (Publ. Princ. Exp. IJI, A, Nr. 21.5) deutet wohl auf ein $\bar{a}$ in dem Gottes-

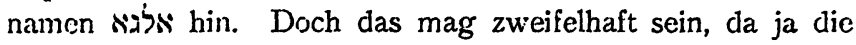
Schreibung ג wirklich vorkommt. Immerhin würde ich den Artikel לs in Nabateiischen durchweg mit al umschreiben, da alle griechischen Formen hicr ein $a$ haben; vgl. $A \beta \delta \alpha \lambda . \gamma o v$,

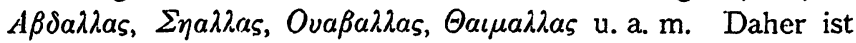
auch besser Wahballāhi denn Wahbullāhi zu schrciben. Zu Z. 7: Der Name גמלת ist wohl Gumullat oder Gumulat

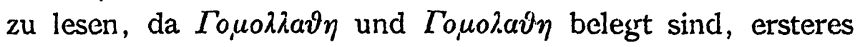
in Publ. Princ. Exp. III, Nr. 363, letzteres ibid. Nr. 305, 346, 380. - Der Name הנר wird Hagar, und nicht Hāgir zu

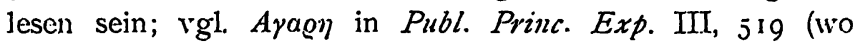
Hagar statt Hagar zu lesen ist), sowie WADD. 2200 und 2405 (= DusSaud-Macler, Mission p. 243 unter Nr. 12).

Z. 8: DalmaN sagt, der Beiname רמה עמה müsse gric-

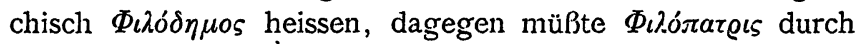
wiedergegeben werclen. Es ist keinc Frage, daß ein so ideal wörtlicher Übersetzer wie Aquila genau so übertragen haben würde. Aber es kommt doch auch schon im Altertum hie und da vor, daß man sinngemäß und nicht buchstabengemäß übersetzt. Wenn also die Nabatäer $\Phi_{i} \grave{\lambda}_{o}-$

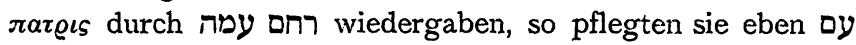

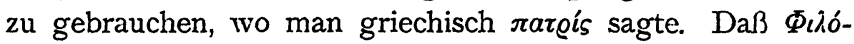
$\delta \eta \mu o s$ stilwidrig sei, hat schon v. GuTSCHMID erklärt; vgl. EutnvG, Nabatäische Inschriften aus Arabien S. 85, Anm. I.

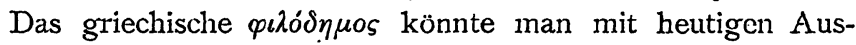
drücken etwa durch "Sozialdemokrat" übersetzen; jedenfalls ist es jemand, der das niedere Volk lieb hat. Außer Arethas IV. haben ja auch Archelaos von Kappadokien und

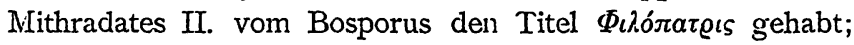
vgl. v. Gurschnim, 1. c.

Nr. 93. Zu עבר־איסי = 'Abd-Isis vgl. oben zu Nr. 3 .

Nr. 98. Zu עמנו vgl. meine Nabataean Inscriptions Nr. 79. DaLMAN führt aus seinen Inschriften "ע Nr. 57 " 
an; aber erstens ist Nr. 67 gemeint und zweitens ist in Nr. 67 עימו zu lesen; s. o.

Das Verzeichnis der nabatäischen Eigennamen (S. $16_{4}$ -166) wïre nun folgendermaßen zu verbessern. Statt אגליאריא

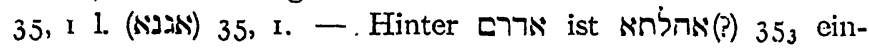
zufügen. - Zu 34 ist ein Fragezeichen zu setzen; vgl. oben zu dieser Inschrift. Gleich dahinter wäre אירן 34 einzuschalten. - Bei $\mathbf{W}$ ' ist die Zahl 82 einzufügen; da-

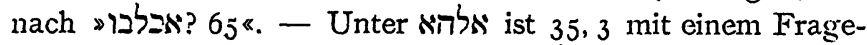
zeichen zu versehen. - Hinter siy stist $7+$ und תמ(?) 6 hinzuzufügen. - Am Ende der mit $\aleph$ beginnenden Wörter ist hinzuzufügen (רשs:?) 7 I und Name בישמא ist zu streichen; vgl. oben zu 92. - Hinter

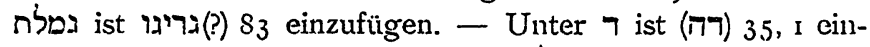
zuschalten. - Die Zahl 82 (?) hinter וארו ואלו ist ein Druckfehler; wofür, habe ich nicht feststellen können. - Die Namen וגעא 7 und ז ובינא 67 sind $\mathrm{zu}$ streichen. - Bei st 89, 3 zu lesen 79, 3; mit »gr. I \& ist 94 gemeint. - Hinter

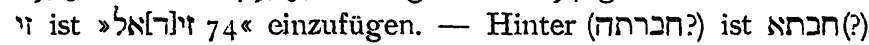

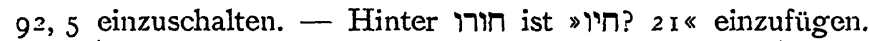
- 31 ist zu streichen; statt dessen ist bei חלר חל dic Zahl $3 \mathrm{I}$ einzufügen, wo auch 94 in $95 \mathrm{zu}$ ändern ist. - Bei

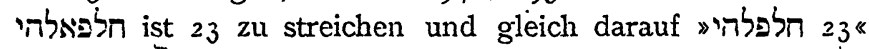
(ohne א!) einzuschalten. - Statt des Namens חלקו

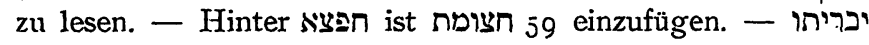

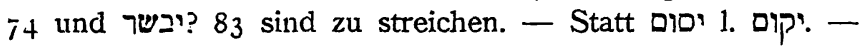
Bei יריבו wäre 84 in $83 \mathrm{zu}$ ändern, wenn nicht die ganze Zeile zu streichen wäre. - Desgleichen ist die folgende Zeile 35,1 zu streichen. - Unter 2 ist אוm? 84 einzufügen. - Bei בלבו

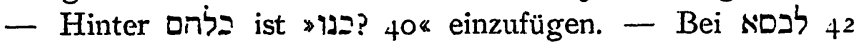

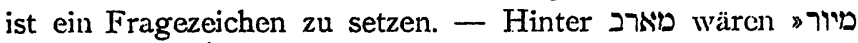

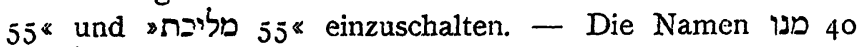

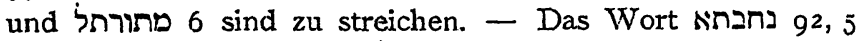
ist zu streichen. - Zu $\mathrm{Z}_{1}$ ist ein Fragezeichen zu machen; wahrscheinlich ist dafür bei שערהלה Zahl 6r 
cinzufügen. - Auch $2 u$ רב 16 ist ein Fragezcichen $z u$ machen; es wäre mindestens (עכד] $z$ yu lesen wie in 8,83 . - Bei עבדאיטי ist die Zahl $\$ 87$ (?)《 cinzuschalten. - Der עברחרהת Name עinter ist עברת ist statt 72,2 die Zahl 73, $2 \mathrm{zu}$ lesen. - $\mathrm{Zu}$ ערנבר ist ein Fragezeichen zu setzen. - Bei עורו ist statt 82 die Zahl 84 zu lesen; bei עירו statt 84 die Zahl 83. - Der Name עשיוש 37 ist zu streichen, statt dessen ist am Schlusse der mit $y$ beginnen-

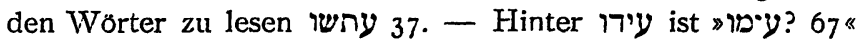
cinzufügcn. - Die ganze Zeile $\gg$ עמ 67. 98《 ist am besten

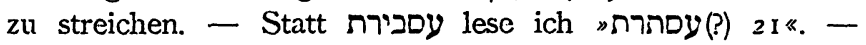

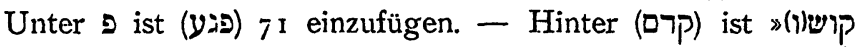

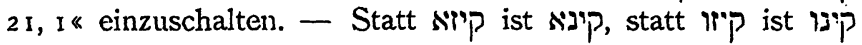

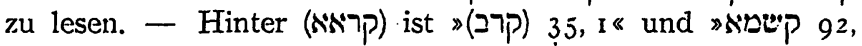
9. I I \& anzufügen. - Hinter רחימו ist

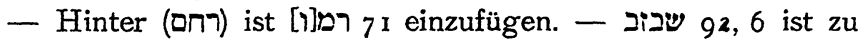
streichen; dafür ist die Zahl bei שיi einzuschieben. - Dic Namen שרהאל 7 ש שרמא 67 sind zu streichen. - Statt

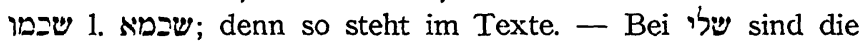
Zahlen $5^{\mathrm{I}}$ und $6 \mathrm{I} \mathrm{zu}$ streichen; oder $6 \mathrm{I}$ wäre $\mathrm{zu}$ streichen und $z u{ }^{1} \mathrm{r}$ ein Fragezeichen zu setzen. Denn in 6r kommt kein Name של של vor und in $5 \mathrm{I}$ ist die Lesung [לי zumdesten sehr zweifelhaft; vgl. meine Bemerkung zu der Inschrift. Die Zahl $\gg 84($ (?) « wäre hinzuzusetzen. - Statt שמיתתאלה ist zu lesen שמיתו; vgl. oben zu Nr.35. - Hinter I 21 תבוקו

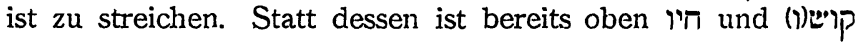
hinzugefügt. - Statt תרמר? ist [Nימי? zu setzen. - Bei תימו ist nach der Zahl 25 (?) die Zahl 35, I einzuschalten. Bei תלמו ist die Zahl 80 mit einem Fragezeichen zu versehen; denn wahrscheinlich ist in 80 ins zu lesen. - Der Name תעמת 59 ist zu streichen. Dafür ist bereits oben eingefügt. 
Anhangsweise sei hier noch auf eine andere interessante Inschrift aus Petra hingewiesen, CIS $\Pi, 427$, von der die Herausgeber des Corpus sagen: Fragmentum quod interpretari non valemus.

רנה נצירך Es ist zu transkribieren ביער Dies ist dein Sieg(?), o Kaiser!«. Ich glaube, daß hierin ein Segenswunsch für den Kaiser enthalten ist,
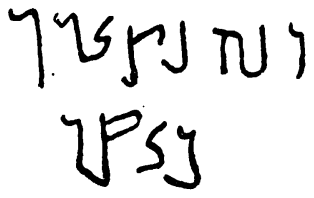

CIS II, 427 . wahrscheinlich für Hadrian, als er den Osten des Reiches besuchte. Cacsar wird sonst arabisch قيص wiedergegeben; im Palmyrenischen, Vog. I I8, scheint auch ביסר vorzukommen. In ביצר hätten wir erst die Assimilation des $D$ an das $p$ und dann die Dissimilation des $p$ zum 2 wegen des folgenden $y$ anzunelimen. Das Wort נציר wird zur arabischen Wurzel ذص gehören. Doch ist die Bedeutung nicht ganz sicher. $\mathrm{Zu}$ dem Inhalte vgl. die griechischen Graffiti, die mit $i \tau \dot{\eta} \chi \eta$. . . . beginnen. 